\title{
DESIGNING OF ADVANCED AND ORIGINAL AUSTEMPERING PROCESSES BASED ON THERMAL SCIENCE AND ENGINEERING PHYSICS APPROACHES
}

\author{
Nikolai Kobasko \\ Intensive Technologies Ltd \\ 68/1 Peremohy Ave., Kyiv, Ukraine, 03113 \\ nkobasko@gmail.com
}

\begin{abstract}
In the paper, a small concentration of inverse solubility polymers in water and other liquid media is recommended to eliminate film boiling by means of reducing initial heat flux density. Quenching steel parts and tools in a small concentration of water solutions under pressure allows performing austempering process just using cold liquids. Its essence consists in coinciding martensite start temperature $\mathrm{M}_{\mathrm{S}}$ with the average temperature of self-regulated thermal process during nucleate boiling mode and further immediate transferring steel parts for tempering at the temperature which exceeds value $\mathrm{M}_{\mathrm{s}}$. The new technology increases the service life of austempered workpieces by more than two times, saves alloy elements, is suitable for larger metallic components, improves environmental conditions, since instead of melted salts and alkali, plain water and water salt solutions can be used. The new austempering process can be used in forging shops to obtain super-strengthened materials in order to switch from alloy steel to plain carbon steels. And it can be also widely used for obtaining nano-bainitic structure in plain carbon steels resulting in saving alloy elements and improving mechanical characteristics of materials.
\end{abstract}

Keywords: film boiling, nucleate boiling, duration, distortion, austempering, pressure, ductility, strength, service life.

(C) Nikolai Kobasko

\section{Introduction}

When quenching steel parts in water or water solutions, local film boiling often can take place resulting in a big distortion and crack formation during hardening. Local film boiling is observed when initial heat flux density $\mathrm{q}_{\text {in }}$ is comparable with the first critical heat flux density $\mathrm{q}_{\text {cr1 }}$. When the initial heat flux density exceeds the critical heat flux density $\mathrm{q}_{\mathrm{cr} 1}$, full film boiling takes place. When the initial heat flux density is less than the critical heat flux density $q_{\text {crr }}$, there is no film boiling. To optimize quenching processes correctly, one should always compare the initial heat flux density with the first critical heat flux density $\mathrm{q}_{\mathrm{cr} 1}$. There is a big problem when calculating the initial heat flux density. The matter is that according to the classical parabolic heat conductivity equation initial heat flux density, as known, is infinity. It means that the full film boiling always should be present during immersion of heated to high temperature steel parts into cold liquid. In reality, initial heat flux density is a finite value which can be calculated solving the hyperbolic heat conductivity equation. Initial heat flux density can be significantly reduced if steel part is quenched in cold polymeric water solutions of inverse solubility. In the paper, a new austempering process is proposed which is performed by quenching steel parts in low concentration polymeric water solutions of inverse solubility under pressure until nucleate boiling is finished. In this case, film boiling is completely prevented. After that, steel parts go to immediate tempering. This core technology of the paper is discussed step by step below.

\section{Initial heat flux densities evaluation}

To make possible initial heat flux density calculation, let's start calculating initial heat flux when the developed transient nucleate boiling process begins. Before it, cold liquid layer around the steel part is heated to boiling point and during that time a surface of steel parts cools drastically since the heat capacity of liquid, for example water, is significantly larger as compared with a steel. Assume that regular thermal process of Kondratjev [1, 2] establishes at the moment of establishing developed transient nucleate boiling process. To be more specific, let's consider an arbitrary shape of a body, for example, very long parallelepiped with a section shown on Fig. 1 covered by a polymeric layer of thickness $\delta$ (Fig. 1). 


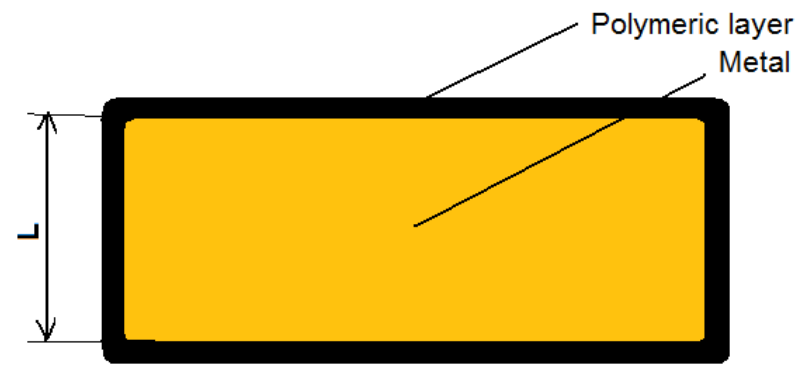

Fig. 1. Section of steel part of height $\mathrm{L}=21$ covered with the polymeric layer of thickness $\delta$

Taking into account existence of polymeric layer, the author [3] proposed an equation for calculating initial heat flux density for any forms of steel parts which is covered with a thin layer of thickness $\delta$. It can be written as:

$$
\mathrm{q}_{\text {in }}=\frac{\lambda \mathrm{KnV}}{\left(1+2 \frac{\delta}{1} \frac{\lambda}{\lambda_{\text {coat }}}\right) \mathrm{KS}}\left(\overline{\mathrm{T}}_{\mathrm{rg}}-\mathrm{T}_{\mathrm{S}}\right),
$$

or

$$
\begin{gathered}
\mathrm{q}_{\mathrm{in}}=\frac{\mathrm{k}_{1} \lambda \mathrm{Kn}}{\left(1+2 \frac{\delta}{1} \frac{\lambda}{\lambda_{\text {coat }}}\right) 1}\left(\overline{\mathrm{T}}_{\mathrm{rg}}-\mathrm{T}_{\mathrm{S}}\right), \\
\frac{\mathrm{V}}{\mathrm{KS}}=\frac{\mathrm{k}_{1}}{\mathrm{l}} ; 1-\frac{\mathrm{L}}{2},
\end{gathered}
$$

where $q_{\text {in }}$ is the initial heat flux density in $\mathrm{W} / \mathrm{m}^{2} ; \mathrm{k}_{1}$ is the coefficient depending on the form of a steel part; $\lambda$ is the thermal conductivity of steel in $\mathrm{W} / \mathrm{mK} ; \lambda_{\text {coat }}$ is the thermal conductivity of the coating (polymeric layer); Kn is the dimensionless Kondratjev number; $\delta$ is the thickness of the polymeric layer in $\mathrm{m}$; 1 is the radius or half of the thickness of the plate in $m$; $\overline{\mathrm{T}}_{\mathrm{rg}}$ is the average temperature at the moment of establishing a regular thermal process; $T_{S}$ is the saturation temperature; $\mathrm{S}$ is the surface in $\mathrm{m}^{2} ; \mathrm{V}$ is the volume in $\mathrm{m}^{3} ; \mathrm{K}$ is the Kondratjev form factor coefficient in $\mathrm{m}^{2}$ (Table 1).

Using equations (1) and (2), engineers can predict local and full film boiling which are not desirable. Some suitable data for calculating initial heat flux densities are provided in Table 1, Table 2 and Table 3.

Table 1

Coefficient $\mathrm{k}_{1}$, surface $\mathrm{S}$, volume $\mathrm{V}$ and Kondratjev form factor $\mathrm{K}$ for different shapes of steel parts

\begin{tabular}{ccccc}
\hline Configuration & $\mathrm{k}_{1}$ & $\mathrm{~S}$ & $\mathrm{~V}$ & $\mathrm{~K}$ \\
\hline Plate of thickness $\mathrm{L}$ & 2.47 & $2 \mathrm{~S}$ & $\mathrm{SL}$ & $\mathrm{L}^{2} / 9.87$ \\
Cylinder & 2.89 & $2 \pi \mathrm{RZ}$ & $\pi \mathrm{R}^{2} \mathrm{Z}$ & $\mathrm{R}^{2} / 5.783$ \\
Cylinder with height $\mathrm{Z}=2 \mathrm{R}$ & 2.75 & $6 \pi \mathrm{R}^{2}$ & $2 \pi \mathrm{R}^{3}$ & $\mathrm{R}^{2} / 8.25$ \\
Long parallelepiped with sides $\mathrm{L}_{1}, \mathrm{~L}_{2}$ & 2.70 & $2 \mathrm{~L}_{1} \mathrm{~L}_{2}+2 \mathrm{~L}_{1} \mathrm{~L}_{3}+2 \mathrm{~L}_{2} \mathrm{~L}_{3}$ & $\mathrm{~L}_{1} \mathrm{~L}_{2} \mathrm{~L}_{3}$ & $\frac{1}{\pi^{2}}$ \\
and $\mathrm{L}_{3}$ & & & $4 \frac{\pi^{2}}{\mathrm{~L}_{2}^{2}}+\frac{\pi^{2}}{\mathrm{~L}_{3}^{2}}$ \\
Sphere & 3.23 & $4 \pi \mathrm{R}^{2}$ & $4 / 3 \pi \mathrm{R}^{3}$ & $\mathrm{R}^{2} / 9.87$ \\
Cube & 3.29 & $6 \mathrm{~L}^{2}$ & $\mathrm{~L}^{3}$ & $\mathrm{~L}^{2} / 29.61$
\end{tabular}


Table 2

Critical heat flux density $\mathrm{q}_{\mathrm{crl}}$ versus water temperature according to Kutateladze and Tolubinsky $[4,5]$

\begin{tabular}{cc}
\hline $\mathrm{T},{ }^{\circ} \mathrm{C}$ & $\mathrm{q}_{\mathrm{cr} 1}, \mathrm{MW} / \mathrm{m}^{2}$ \\
\hline 5 & $6.60-7.06$ \\
20 & $5.50-5.90$ \\
40 & $3.33-3.57$ \\
100 & $2.25-2.40$ \\
& $1.27-1.185$
\end{tabular}

Table 3

Critical heat flux densities $\mathrm{q}_{\mathrm{cr} 1}$ of salt and alkali water solutions at their optimal concentration in $\mathrm{MW} / \mathrm{m}^{2}$

\begin{tabular}{ccc}
\hline Quenchant & $\mathrm{q}_{\mathrm{crl}}, \mathrm{MW} / \mathrm{m}^{2}$ & Authors \\
\hline $12 \%$ water solution of $\mathrm{NaCl}$ at $20{ }^{\circ} \mathrm{C}$ & 11 & {$[6,7]$} \\
$5-12 \%$ water solution of $\mathrm{NaOH}$ at $20{ }^{\circ} \mathrm{C}$ & $10-13$ & {$[6]$} \\
$12 \%$ water solution of $\mathrm{CaCl} 2$ at $20{ }^{\circ} \mathrm{C}$ & 12 & \\
Table 4 & & $\mathrm{q}_{\mathrm{in}}, \mathrm{MW} / \mathrm{m}^{2}$ \\
Initial heat flux densities qin in $\mathrm{MW} / \mathrm{m}^{2}$ for cylinders at the moment of establishment of developed \\
transient nucleate boiling process during quenching in water at $20{ }^{\circ} \mathrm{C}$ & 11,9 \\
Diameter, mm & 7,11 \\
6 & 3,56 \\
10 & 1,78 \\
40 & 1,42
\end{tabular}

As seen from Table 4, initial heat flux density for cylinders of $20 \mathrm{~mm}$ is equal to $3.56 \mathrm{MW} / \mathrm{m}^{2}$. Critical heat flux density for water at $20{ }^{\circ} \mathrm{C}$ is $5.5 \mathrm{MW} / \mathrm{m}^{2}$, i. e. $\mathrm{q}_{\text {in }}<\mathrm{q}_{\mathrm{cr}}$. It means that any kind of film boiling is absent. However, for cylindrical specimen $6 \mathrm{~mm}$ in diameter, film boiling takes place since $\mathrm{q}_{\mathrm{in}} \quad \mathrm{q}_{\mathrm{cr} 1}$. Film boiling can be eliminated for small specimens if water contains a small amount of inverse solubility polymer which creates a thin insulating layer that reduces initial heat flux. It is known that thermal conductivity of polymers is very low. For example, the thermal conductivity of polystyrene is $0.14 \mathrm{~W} / \mathrm{mK}$ and thermal conductivity of polytetrafluoroethylene is $0.34 \mathrm{~W} / \mathrm{mK}$. Assume that the thermal conductivity of inverse solubility polymer is $0.22 \mathrm{~W} / \mathrm{mK}$. Then taking into account that data and using equation (1), one can calculate the initial heat flux density for a small cylinder if the thickness of the layer is known. Assume that it is $0.1 \mathrm{~mm}$. Then using Eq. (2), we have

$$
\mathrm{q}_{\text {in }}=\frac{\mathrm{k}_{1} \lambda \mathrm{Kn}}{\left(1+2 \frac{\delta}{\mathrm{R}} \frac{\lambda}{\lambda_{\text {coat }}}\right) \mathrm{R}}\left(\overline{\mathrm{T}}-\mathrm{T}_{\mathrm{S}}\right)=\frac{2.89 \times 22 \mathrm{~W} / \mathrm{mK} \times 0.8}{\left(1+2 \frac{0.0001 \mathrm{~m}}{0.003 \mathrm{~m}} \times \frac{22 \mathrm{~W} / \mathrm{mK}}{0.22 \mathrm{~W} / \mathrm{mK}}\right) \times 0.003 \mathrm{~m}}\left(800^{\circ} \mathrm{C}-100^{\circ} \mathrm{C}\right)=1.54 \frac{\mathrm{MW}}{\mathrm{m}^{2}} .
$$

In this case, the initial heat flux density $q_{\text {in }} \ll q_{\text {cr1 }}$ (Table 2, Table 4). It means that there is no possibility for the film boiling. Note that during quenching of steel probe in vegetable oils in many cases film boiling is absent completely. It is due to creation insulating layer at the surface of tested probe caused by oxidation of the vegetable oil. 
It turned out that inverse solubility polymers can be used to eliminate completely film boiling and by that way intensify quenching processes which decrease significantly distortion and increase the strength of materials. It is a new approach based on engineering physics and thermal science achievements.

\section{Quenching under pressure}

Pressure increases the first critical heat flux density and the average temperature of self-regulated thermal process (Fig. 2, Fig. 3) [6, 8, 9].



Fig. 2. First critical heat flux density $\mathrm{q}_{\mathrm{cr} 1}$ versus pressure and temperature of water $[6,7]$

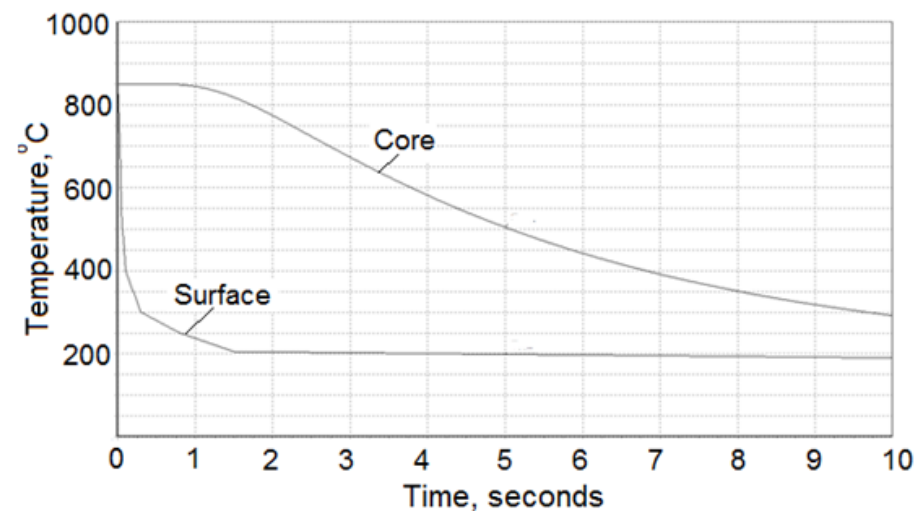

Fig. 3. Surface and core temperature versus time for cylindrical specimen $20 \mathrm{~mm}$ in diameter made of AISI 304 steel and quenched from $850{ }^{\circ} \mathrm{C}$ in cold water under pressure $1 \mathrm{MPa}$

Table 5

Water saturation temperature versus pressure

\begin{tabular}{cc}
\hline $\mathrm{P}, \mathrm{MPa}$ & $\mathrm{T}_{\mathrm{s}},{ }^{\circ} \mathrm{C}$ \\
\hline 0,1 & 99,6 \\
0,2 & 120,2 \\
0,3 & 133,5 \\
0,4 & 143,6 \\
0,5 & 151,8 \\
0,6 & 158,8 \\
0,7 & 165 \\
0,8 & 170,4 \\
0,9 & 175,4 \\
1 & 180 \\
2 & 212,4
\end{tabular}


Table 6

Convective $\mathrm{HTC}_{\mathrm{S}}$ versus pressure ( $\mathrm{MPa}$ ) and temperature of water

\begin{tabular}{cccc}
\hline $\mathrm{P}, \mathrm{MPa}$ & Water $10^{\circ} \mathrm{C}$ & Water $20^{\circ} \mathrm{C}$ & \multicolumn{2}{c}{ Water $30^{\circ} \mathrm{C}$} \\
& $\alpha_{\text {conv }}, \mathrm{W} / \mathrm{m}^{2} \mathrm{~K}$ & $\alpha_{\text {conv }}, \mathrm{W} / \mathrm{m}^{2} \mathrm{~K}$ & $\alpha_{\text {conv }}, \mathrm{W} / \mathrm{m}^{2} \mathrm{~K}$ \\
\hline 0,1 & 548 & 640 & 1015 \\
0,2 & 586 & 690 & 1105 \\
0,3 & 609 & 719 & 1156 \\
0,4 & 625 & 740 & 1196 \\
0,5 & 638 & 756 & 1223 \\
0,6 & 648 & 769 & 1246 \\
0,7 & 657 & 780 & 1265 \\
0,8 & 664 & 790 & 1280 \\
1,0 & 670 & 798 & 1295
\end{tabular}

As one can see from Fig. 3, the surface temperature of cylindrical specimen drops within $1.5 \mathrm{sec}$ almost to boiling point of water (Table 5) and then maintains at that level 9 seconds until convection starts. The higher the convective heat transfer coefficient (HTC) is, the shorter of self- regulated thermal process is and quicker convection starts. Convective HTCs are provided in Table 6. However, during nucleate boiling process surface temperature reduces very slowly (Table 7). Instead of that, the intensity of the transient nucleate boiling process is very high. HTCs during nucleate boiling reach values $200 \mathrm{KW} / \mathrm{m}^{2} \mathrm{~K}$ and more (Fig. 4).

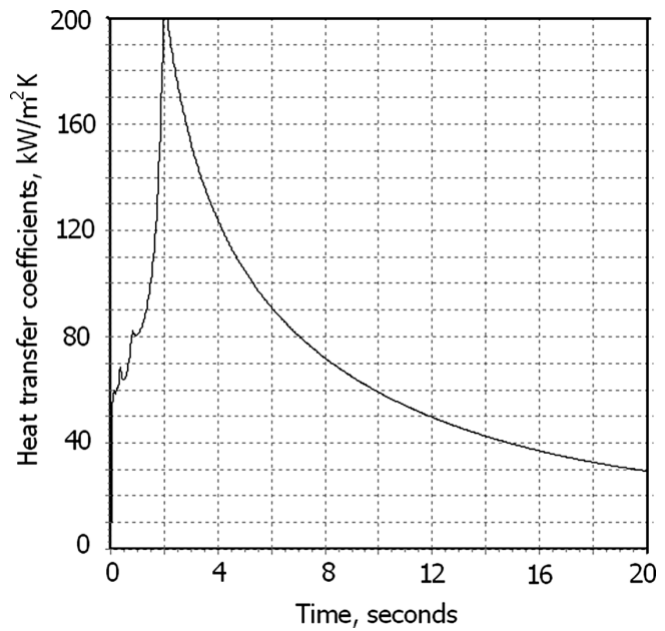

Fig. 4. The real heat transfer coefficients versus time for a sphere of $38.1 \mathrm{~mm}$ in diameter quenched from $875^{\circ} \mathrm{C}$ in a $5 \%$ aqueous $\mathrm{NaOH}$ solution at $20^{\circ} \mathrm{C}$ [7]

\section{Table 7}

Initial and ending temperature of the full transient nucleate boiling process and its duration versus pressure (MPa) for an infinite cylinder of $20 \mathrm{~mm}$ in diameter when quenching in water at $20{ }^{\circ} \mathrm{C}$

\begin{tabular}{cccc}
\hline Pressure, $\mathrm{MPa}$ & Initial temperature, ${ }^{\circ} \mathrm{C}$ & Ending temperature, ${ }^{\circ} \mathrm{C}$ & $\begin{array}{c}\text { Duration of transient nucleate } \\
\text { boiling process, seconds }\end{array}$ \\
\hline 0.1 & 126 & 108 & 14 \\
0.4 & 169 & 155 & 12 \\
0.7 & 190 & 175 & 11 \\
1.0 & 205 & 190 & 10.5
\end{tabular}


Duration of transient nucleate boiling can be calculated using equation (4) [10-12]

$$
\tau_{\mathrm{nb}}=\bar{\Omega} \mathrm{k}_{\mathrm{F}} \frac{\mathrm{D}^{2}}{\mathrm{a}}
$$

Here $\tau_{\mathrm{nb}}$ is the duration of the transient nucleate boiling process in seconds; $\bar{\Omega}$ is characteristic of a quenchant when the austenitizing temperature is fixed at $850{ }^{\circ} \mathrm{C} ; \mathrm{k}_{\mathrm{F}}$ is coefficient responsible for a geometrical form of a steel part; $\mathrm{D}$ is the size (thickness or diameter) in $\mathrm{m}$; a is the thermal diffusivity of a material in $\mathrm{m}^{2} / \mathrm{s}[13]$.

It should be underlined that real heat transfer coefficients (HTCs) provided in Fig. 4 are calculated as a ratio $\alpha=\frac{q}{T_{s f}-T_{S}}$. Often engineers use effective HTCs for calculating nucleate boiling processes which is a ratio $\alpha=\frac{q}{T_{s f}-T_{m}}$. Here $\alpha$ is HTC; $q$ is the heat flux density; $T_{\text {sf }}$ is the surface temperature; $\mathrm{T}_{\mathrm{S}}$ is the saturation temperature; $\mathrm{T}_{\mathrm{m}}$ is the medium temperature. Boiling process is a function of overheat $T_{s f}-T_{S}$ and doesn't depend significantly on underheat $T_{S}-T_{m}$. That is why, temperature fields during nucleate boiling processes should be calculated using real HTCs.

\section{Austempering process performed in low concentration of polymers under pressure}

Taking into account the absence of film boiling in cold water polymeric solutions of low concentration and possibility of increasing the average temperature of the self - regulated thermal process by adjusting pressure, one can perform the austempering process using cold liquids. The procedure is as follows:

1. A water polymeric solution of low concentration (up to $2 \%$ ) is prepared which is used as a quenchant in the apparatus where cooling from high temperature $\left(850^{\circ} \mathrm{C}\right)$ takes place.

2. A sample made of AISI steel W1 with martensite start temperature $200{ }^{\circ} \mathrm{C}$, for example cylinder of $20 \mathrm{~mm}$ in diameter, is immersed into $2 \%$ water polymeric solution (2\%) of inverse solubility under pressure $1 \mathrm{MPa}$ and is kept in solution for 10 seconds (Fig. 3 and use Eq. (4)).

3 . The sample is quickly taken out of solution and put immediately into furnace for tempering at $200{ }^{\circ} \mathrm{C}$. Duration of tempering is 2 hours.

The technology requires special installation similar to vacuum furnaces. However, for high carbon steels and irons with the martensite start temperature of $100{ }^{\circ} \mathrm{C}$, conventional technological lines can be used for performing austempering at normal atmospheric pressure.

\section{Discussion}

Self - regulated thermal process, discovered by the author, was used for developing intensive technologies called IQ-2 and intensive austempering processes [14-20]. The new technologies were developed and patented in Ukraine and are used in US [7, 21]. Especially, excellent results are obtained in the heat treating industry for rolls made of Ductile Irons [16, 21, 22]. The proposed technologies are improved by creating an insulating layer on the surface of quenched steel parts that decreases initial heat flux density. It eliminates local and full film boiling completely during hardening.

Mathematicians Prof. Buikis, Prof. Guseynov and their colleagues paid serious attention to solving hyperbolic heat conductivity equations with the appropriate boundary conditions responsible for transient nucleate boiling processes [23-27]. Now, engineers and metallurgists are looking forward to obtaining practical data, based on the hyperbolic equation, to be easily used for recipes development for different configuration of steel parts during quenching. Especially, initial heat flux densities are important since they allow to predict possible local film boiling. Local film boiling is the main reason for big distortion. Bearing industry spends a lot of money (millions) to reduce distortion of bearing rings. Proposed engineering physics approach, discussed in the paper, can help minimize distortion of different steel parts after quenching. Developed new austempering processes can reduce radically distortion of steel parts after hardening and increase significantly strength of materials [28]. 


\section{Conclusions}

1. For the first time, it is recommended to use small concentrations of inverse solubility polymers in water and other liquid media to eliminate any kind of film boiling by means of reducing initial heat flux density.

2. It is proposed to quench steel parts in small-concentration water solutions under pressure where the advanced austempering process can be performed. The new technology increases the service life of austempered steel parts, saves alloy elements, is suitable for larger steel parts, improves environmental conditions since instead of melted salts and alkali plain water and water salt solutions can be used.

3. The new austempering process can be used in forging shops to obtain super-strengthened materials in order to switch from alloy steel to plain carbon steels. And it can be also widely used for obtaining nano - bainitic structure in plain carbon steels resulting in saving alloy elements and improvement of mechanical characteristics [28].

\section{References}

[1] Kondratjev, G. M. (1954). Regulyarnyi Teplovoy Rezhim (Regular Thermal Mode), Gostekhizdat, Moscow.

[2] Kondratjev, G. M. (1957). Teplovye Izmereniya (Thermal measurements), Mashgiz, Moscow.

[3] Kobasko, N. I. (2012). Real and Effective Heat Transfer Coefficients (HTCs) Used for Computer Simulation of Transient Nucleate Boiling Processes During Quenching. Materials Performance and Characterization, Vol. 1, Issue 1, 1-20. doi: 10.1520/mpc-2012-0012

[4] Tolubinsky, V. I. (1980). Heat Transfer at Boiling, Naukova Dumka, Kyiv, 315.

[5] Kutateladze, S. S. (1952). Heat Transfer at Condensation and Boiling, Mashgiz, Moscow.

[6] Kobasko, N. I. (1980). Steel Quenching in Liquid Media Under Pressure. Naukova Dumka, Kiev, 206.

[7] Kobasko, N. I., Aronov, M. A., Powell, J. A., Totten, G. E. (2010). Intensive Quenching Systems: Engineering and Design. ASTM International, West Conshohocken, USA, 234. doi: 10.1520/mnl64-eb

[8] Kobasko, N. I. (2005). Self-regulated Thermal Processes During Quenching of Steels in Liquid Media. International Journal of Microstructure and Materials Properties, Vol. 1, Issue 1, 110-125. doi: 10.1504/ijmmp.2005.008135

[9] Kobasko, N. I. (1998). Self-Regulated Thermal Process at Steel Quenching. Promyshlennaya Teplotekhnika, Vol. 20, Issue 5, 10-14.

[10] Kobasko, N. I. (2009). Transient Nucleate Boiling as a Law of Nature and a Basis for Designing of IQ Technologies. Proc. of the 7th IASME/WSEAS International Conference on Heat Transfer, Thermal Engineering and Environment (HTE’09), Moscow, Aug. 20-22, 67-76.

[11] Kobasko, N. I. (2012). Discovered Characteristics of the Transient Nucleate Boiling Process to Be Widely Used for Testing Materials and New Technologies Development. In a Book "Resent Advances in Fluid Mechanics \& Mass Transfer and Biology”, WSEAS Press, Harvard, Cambridge, 15-22.

[12] Kobasko, N. I. (2014). Phenomena Discovered During Immersion of Steel Parts Into Liquid Quenchants. IMEPEG, Vol. 23, Issue 12, 4211-4215. doi: 10.1007/s11665-014-1223-1

[13] Kobasko, N. I. (2011). Duration of the Transient Nucleate Boiling Process and Its Use for the Development of New Technologies. Journal of ASTM International, Vol. 8, Issue 7, 103485. doi: 10.1520/jai103485

[14] Kobasko, N. I. (1992). Intensive Steel Quenching Methods. Theory and Technology of Quenching. B. Liscic, H. M. Tensi, and W. Luty, Eds., Springer-Verlag, Berlin, New York, Tokyo, 367-389.

[15] Kobasko, N. I. (2015). Isothermal Method for Hardening of High Carbon Steels and Irons. UA Patent No. 109935, registered on Oct. 26.

[16] Aronov, M. A., Kobasko, N. I., Powell, J., Andreski, B., O’Rourke, B. (2014). Intensive Quenching Processes: Basic Principles and Commercialization. Proc. of the European Conference on Heat Treatment and 21st IFHTSE Congress, Munich, Germany, May, 12th-15th, 267-274.

[17] Kobasko, N. I. (2013). Tribological Properties of Intensively Quenched Materials. Encyclopedia of Tribology, Q. Jane Wang, Yip-Wah Chung, Eds., Springer US, 3811-3816. doi: 10.1007/978-0-387-92897-5_1023.

[18] Kobasko, N. I. (2010). Intensive Steel Quenching Methods. Quenching Theory and Technology (Second Edition), B. Liscic, H. M. Tensi, L. C. F. Canale, G. E. Totten, Eds., CRC Press, London, New York, 509-567. 
[19] Kobasko, N. (2014). An Overview on IQ-2 Processes. Their Present and Future. In a Book "Recent Advances in Intelligent Control, Modeling and Simulation", Hitoshi Kijima, Ed., WSEAS Press, Cambridge, MA, 46-56.

[20] Kobasko, N. I., Aronov, M. A., Powell, J. A., Ferguson, B. L. (2014). Verification of Presence of Direct Convection Mode of Heat Transfer During Intensive Quenching in High Velocity IQ System. "Recent Advances in Intelligent Control, Modeling and Simulation”, Hitoshi Kijima, Ed., WSEAS Press, Cambridge, MA, 165-170.

[21] Aronov, M. A., Kobasko, N. I., Powell, J. A., Kim, H., O’Rourke, B., Andreski, B. (2015). Application of intensive quenching process for steel mill rolls made of ductile iron. Materials Science and Technology (MS\&T) Conference, Greater Columbus Convention Center, Columbus, Ohio, USA.

[22] Kobasko, N. I., Aronov, M. A., Ichitani Katsumi, Hasegawa Mayu, Noguchi Kenro. (2012). High Compressive Residual Stresses in Through Hardened Steel Parts as a Function of Biot Number. In a Book "Recent Advances in Fluid Mechanics, Heat and Mass Transfer and Biology", Manoj K. Jha, Myriam Lazard, Azami Zaharim, K. Sopian, Eds., WSEAS Press, Cambridge, MA, USA, 35-40.

[23] Kobasko, N. I., Guseynov, Sh. E. (2008). Initial Heat Flux Densities and Duration of Non-stationary Nucleate Boiling During Quenching. Proceedings of the 5th WSEAS International Conference on Heat and Mass Transfer (HMT '08), Acapulco, Mexico, 104-109.

[24] Bobinska, T., Buike, M., Buikis, A. (2010). Hyperbolic heat equation as mathematical model of steel quenching of L- shape samples. Proc. of the 5th IASME/WSEAS Int. Conf. on Continuum Mechanics, Fluids, Heat, Cambridge, UK, WSEAS Press, 21-26.

[25] Guseynov, Sh. E., Buikis, A., Kobasko, N. I. (2006). Mathematical statement of a problem with the hyperbolic heat transfer equation for the intensive steel quenching processes and its analytical solution. Proceedings of the Seventh International Conference "Equipment and Technologies for Heat Treatment of Metals and Alloys" (OTTOM-7), Vol. 2, Kharkov, Ukraine, 22-27.

[26] Guseynov, Sh. E., Kobasko, N. I. (2008). On One Nonlinear Mathematical Model for Intensive Steel Quenching and its Analytical Solution in Closed Form. The 5th WSEAS Int. Conf. on Heat and Mass transfer (HMT'08), Acapulco, Mexico.

[27] Buikis, A. (2009). Some new models and their solutions for intensive steel quenching. Abstracts of MMA Daugavpils, Latvia, May $27-30$.

[28] Bhadeshia, H. K. D. H. (2015). Bainite in Steels: Theory and Practice (3rd edition), Money Publishing, 616. 